\title{
Prevalence of MTHFR C677T polymorphism in north Indian mothers having babies with Trisomy 21 Down syndrome
}

\author{
Utkarsh Kohli, Sadhna Arora, Madhulika Kabra, Lakshmy Ramakrishnan', Sheffali \\ Gulati and Ravindra Mohan Pandey ${ }^{2}$
}

Recent studies have evaluated possible links between polymorphisms in maternal folate metabolism genes and Down syndrome. Some of these studies show a significantly increased prevalence of the C677T polymorphism of the 5,10-methylene tetrahydrofolate reductase (NADPH) gene (MTHFR) among mothers who have had babies with Down syndrome. This study examined the prevalence of the MTHFR C677T polymorphism among 104 north Indian mothers of babies with Down syndrome and 109 control mothers. The prevalence of MTHFR C677T polymorphism observed among mothers of babies with Down syndrome was $28 \%$ compared to $35 \%$ in controls (C677T/T677T). There was no significant difference between the two groups $(p=0.294)$. Mean homocysteine level in mothers of children with Down syndrome was lower than the level in the controls. Our data suggests that the MTHFR C677T polymorphism is not associated with an increased risk of Down syndrome in the north Indian population. Homocysteine levels in our study were higher when compared to other studies. Methylcobolamin and folate deficiency or use of random samples for homocysteine determination could possibly account for this observation.

(1) Departments of Paediatrics, Cardiac Biochemistry and (2) Biostatistics, All India Institute of Medical Sciences, New Delhi110029.

Correspondence to $\mathrm{Dr}$ Madhulika Kabra • e-mail: mkabra_aiims@yahoo.co.in / mkabra_aiims@rediffmail.com

doi:10.3104/reports.2004

(c) 2007 The Authors. Journal Compilation @ 2008 Down

Syndrome Education International.
Down syndrome is the most common chromosome disorder in humans. The extra chromosome is derived from the mother in $94 \%$ of cases and is due to non-disjunction during meiosis. At present, advanced maternal age ( $>35$ years) at the time of conception is the only well known risk factor for Down syndrome ${ }^{[1]}$. In the last few years, a number of studies have evaluated a possible link between polymorphisms in maternal folate metabolism genes and Down syndrome ${ }^{[2-4]}$. Some of these studies show a significantly increased prevalence of certain polymorphisms in folate metabolism genes, namely the 5,10-methylene tetrahydrofolate reductase (NADPH) gene and the 5-Methyltetrahydrofolate-homocysteine methyltransferase reductase gene (MTRR) among mothers who have had babies with Down syndrome ${ }^{[3,5]}$.

This study was undertaken with the aim of finding out the prevalence of the MTHFR C677T polymorphism in north Indian mothers of babies with Down syndrome and comparing it with appropriate controls, since no such studies were available from India. The MTHFR C677T polymorphism raises the dietary need of folic acid to maintain normal remethylation of homocysteine to methionine, hence, it was decided to measure homocysteine levels and calculate folate intake in mothers of babies with Down syndrome and compare it with control mothers.

\section{Study population and sample collection}

In our study, the mothers of trisomy 21 patients of north Indian ethnicity, attending the genetic clinic, morning Out Patient Department (OPD), and admitted in the paediatric ward, were enrolled after an informed written consent. 10 $\mathrm{ml}$ of blood was collected from these patients ( $5 \mathrm{ml}$ for plasma homocysteine levels and $5 \mathrm{ml}$ for DNA analysis for the MTHFR C677T mutation). Plasma homocysteine levels were done at the Cardiac biochemistry laboratory, Cardio- 
Neuro Center, and DNA analysis for the MTHFR C677T polymorphism was done at the Genetic Unit, Department of Paediatrics. A questionnaire was filled in and dietary history was taken by 24 hour recall method.

The study group included 104 north Indian mothers of babies with Down syndrome. Inclusion criteria were: (1) mothers with a history of having a baby with trisomy 21 ; (2) age $<30$ yrs at the time of birth of the baby; and (3) north Indian ethnicity. Exclusion criteria were (1) maternal age $>30$ yrs; (2) past history of Neural tube defects or other malformations in previous pregnancies; (3) translocation karyotype in baby affected with Down syndrome; (4) parents not consenting; (5) ethnicity other than north Indian; and (6) history of early myocardial infarction (Males $<55$ yrs, Females $<60$ yrs) in the family and (7) recurrent pregnancy loss.

We enrolled 109 north Indian mothers, without a history of Down syndrome and Neural tube defects in previous babies, and aged $<30 \mathrm{yr}$ at the time of birth of their first baby as controls. They were chosen from the OPDs/clinics/mothers coming to the genetic unit for other tests, after an informed written consent.

\section{Laboratory procedures}

$10 \mathrm{ml}$ of blood was collected in EDTA vials, $5 \mathrm{ml}$ each for molecular studies and bio-chemical analysis (plasma homocysteine). DNA was extracted by salt extraction method ${ }^{[6]}$. After extracting DNA from the blood samples, the DNA was subjected to polymerase chain reaction $(\mathrm{PCR})^{[7]}$. The PCR primer sequences and conditions used were as follows: Forward-5'GAA GCA GGG AGE TIT GAG GC-3' ; Reverse-5'CCC ATG TCG GTC CAT CCC TT-3'. Extracted DNA was digested by overnight action of Taq 1 enzyme at $65^{\circ} \mathrm{C}$. The product was run on $8 \%$ polyacrylamide gel electrophoresis (PAGE) to analyse for the MTHFR C677T polymorphism (FIGURE 1).

For the plasma homocysteine assay, blood was transported to the laboratory at a temperature of around $4^{\circ} \mathrm{C}$. The sample was centrifuged at 3000 rpm for 15 minutes and the plasma was separated. Mixed disulphide and protein bound forms of homocysteine in the sample were reduced to free homocysteine by use of dithiothretiol (DTT) ${ }^{[8]}$. Homocysteine in the test sample was converted to S-adenosyl-L-homocysteine (SAH) by the use of SAH hydrolase in presence of excess of adenosine. The solid-phase enzyme immunoassay was based on competition between S-adenosyl homocysteine (SAH) in the sample and immobilised SAH bound to the walls of the micrometer plate for binding sites on a monoclonal anti-SAH

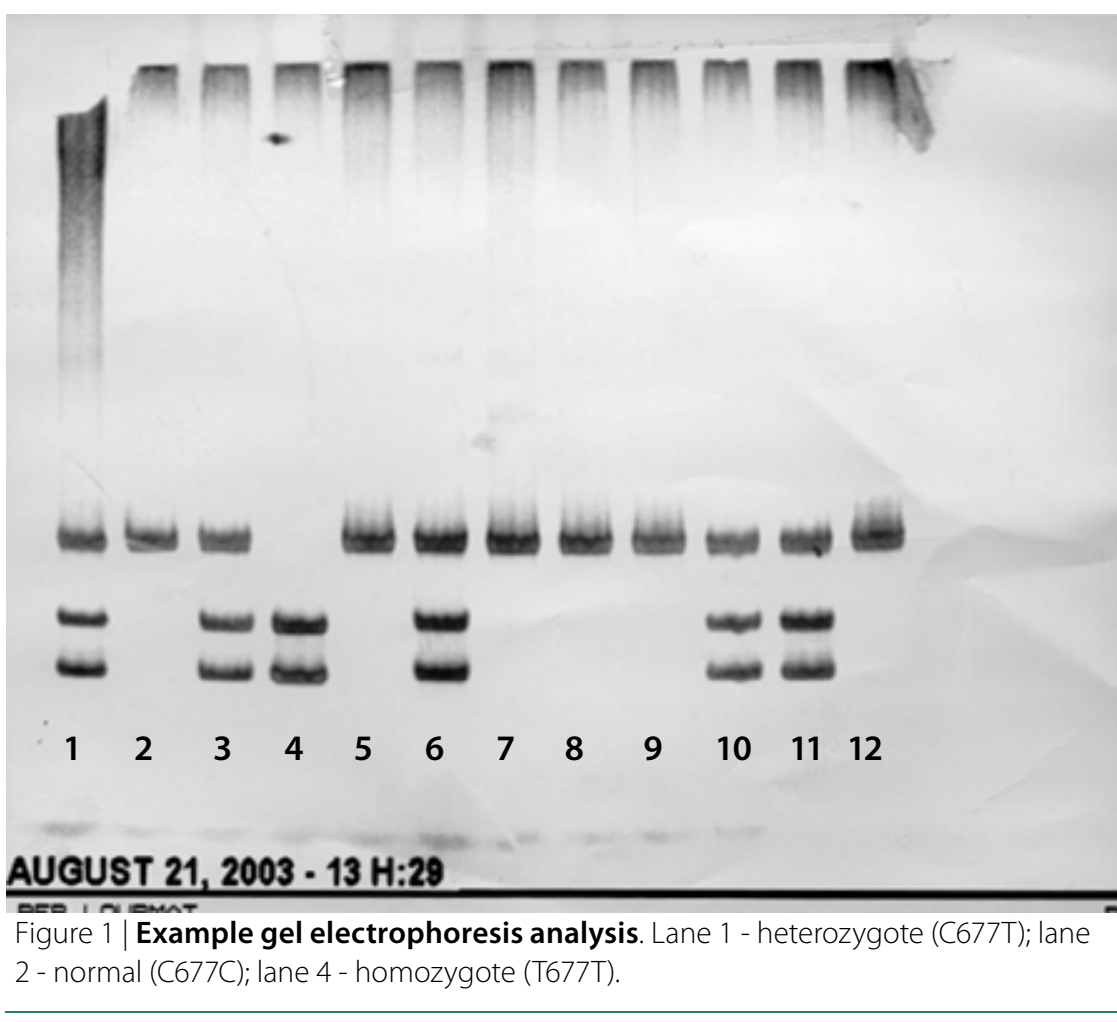

antibody. After removal of unbound anti-SAH antibody, a secondary rabbit antimouse antibody labelled with the enzyme horse radish peroxidase (HRP) was added. The peroxidase activity was measured spectrophotometrically after addition of substrate. Absorbance was inversely related to the concentration of total homocysteine in the sample.

Twenty four hour dietary recall method was used to take dietary history. The folate content of the diet was calculated as per ICMR reference charts ${ }^{[9]}$. The data was analysed using SPSS software for Windows (Version 10.0.01). The difference between proportions and means was analysed using Pearson chi square and t-test, respectively. $p<0.05$ was taken as level of significance.

\section{Results}

In our study, we enrolled 104 north Indian mothers of babies with trisomy 21 Down syndrome (cases) and 109 controls. The highest proportion of both the cases and controls were from Uttar Pradesh (36\% cases and 39\% controls). There was no significant difference in the origin of cases and controls $(p=0.88)$.

All mothers were under 30 years of age at the time of birth of the baby with Down syndrome. The mean present age of mothers of babies with Down syndrome was $27.5 \mathrm{yrs}$ and the mean present age of the control mothers was 28.9 yrs. There was no significant difference in the present ages of two groups.

MTHFR C677T polymorphism analysis was 


\begin{tabular}{|c|c|c|c|c|}
\hline \multirow[t]{2}{*}{ MTHFR } & \multicolumn{2}{|c|}{ Cases } & \multicolumn{2}{|c|}{ Controls } \\
\hline & $n$ & $\%$ & $\mathrm{n}$ & $\%$ \\
\hline C677C & 74 & 72 & 71 & 65 \\
\hline С677T/T677T & 29 & 28 & 38 & 35 \\
\hline Total & 103 & & 109 & \\
\hline \multicolumn{5}{|c|}{$\begin{array}{l}\text { Table } 1 \text { | MTHFR C677T polymorphism distribution of } \\
\text { cases and controls. }\end{array}$} \\
\hline
\end{tabular}

completed for 103 cases and all 109 controls. 71\% of mothers of babies with Down syndrome had the C677C polymorphism, 28\% had the C677T (heterozygous) polymorphism while none were homozygous for the $\mathrm{T}$ polymorphism. Among the controls, $65 \%$ had the $\mathrm{C} 677 \mathrm{C}$ polymorphism, $29 \%$ were heterozygous for the T allele (C677T) while $6 \%$ were homozygous for the $\mathrm{T}$ allele (TABLE 1). However, when heterozygotes and homozygotes were combined together, there was no significant difference between the two groups.

We also measured random plasma homocysteine levels for 92 cases and 91 controls. Homocysteine levels for other patients could not be measured as blood samples were haemolysed. Mean homocysteine level in the cases and controls was $12.26 \pm 5.95 \mathrm{umol} / \mathrm{L}$ and $17.33 \pm 7.22$ umol/L, respectively. Two-sample $t$ test with equal variances was used to analyse the difference between means in two groups. $t$ and $p$ values were 5.18 and 0.0001 , respectively. The results are summarised in TABLE 2.

Mean folate intake was calculated in both cases and controls based on 24 hour dietary recall. The average 24 hour folate intake in cases and controls was $157.63 \pm 74.03 \mu \mathrm{g}$ and $143 \pm 66.0 \mu \mathrm{g}$, respectively. The folate intake in cases was higher than that in controls but the difference was not significant $(p=0.1414)$. A non significant negative correlation was found between folate intake and homocysteine levels in the C677T polymorphism positive cases. No correlation could be found between homocysteine levels and folate intake in other groups.

\begin{tabular}{|c|c|c|c|c|c|c|c|c|}
\hline \multirow[t]{2}{*}{ Genotype } & \multicolumn{4}{|c|}{ Down syndrome mothers } & \multicolumn{4}{|c|}{ Control mothers } \\
\hline & $\begin{array}{r}\mathrm{C} / \mathrm{C} \\
(\%)\end{array}$ & $\begin{array}{l}\mathrm{C} / \mathrm{T} \\
(\%)\end{array}$ & $\begin{array}{l}\mathrm{T} / \mathrm{T} \\
\text { (\%) }\end{array}$ & $\begin{array}{r}\mathrm{CT} / \mathrm{TT} \\
(\%)\end{array}$ & $\begin{array}{l}C / C \\
\text { (\%) }\end{array}$ & $\begin{array}{l}\mathrm{C} / \mathrm{T} \\
(\%)\end{array}$ & $\begin{array}{l}\mathrm{T} / \mathrm{T} \\
\text { (\%) }\end{array}$ & $\begin{array}{r}\mathrm{CT} / \mathrm{TT} \\
(\%)\end{array}$ \\
\hline James et al..$^{[3]}$ & 26.3 & 56.9 & 14.0 & 73.6 & 48.0 & 44.0 & 8.0 & 52.0 \\
\hline Hobbs et al. ${ }^{[2]}$ & 32.0 & 54.0 & 14.0 & 68.0 & 48.0 & 42.0 & 10.0 & 52.0 \\
\hline Stuppia et al. ${ }^{[10]}$ & 31.0 & 50.7 & 18.3 & 69.0 & 24.1 & 55.4 & 20.5 & 75.9 \\
\hline O'Leary et al. ${ }^{[5]}$ & 44.0 & 51.0 & 5.0 & 57.0 & 47.0 & 44.0 & 9.0 & 53.0 \\
\hline Sheth et al. ${ }^{[4]}$ & 71.4 & 25.0 & 3.5 & 28.5 & 46.2 & 46.1 & 7.7 & 53.8 \\
\hline Our study & 71.8 & 28.2 & 0.0 & 28.2 & 65.1 & 29.4 & 5.5 & 34.9 \\
\hline
\end{tabular}

Table 3 | MTHFR polymorphisms across various studies.

\section{Discussion}

In our study, we included 104 north Indian mothers of babies with trisomy 21 . All these mothers had borne babies at or before 30 years of age. As controls, we enrolled 109 north Indian mothers who had never had a baby with Down syndrome or Neural tube defect and had borne at least one baby before 30 years of age. We measured random plasma homocysteine levels for 92 mothers of babies with Down syndrome and 91 control mothers. We also calculated 24 hour folate intake as per ICMR charts.

Our data showed that the prevalence of MTHFR C677T polymorphism in north Indian mothers of babies with trisomy 21 Down syndrome was $28 \%$ compared to $35 \%$ in controls (C677T/ T677T). The only other Indian data available for Gujrati women, reported by Sheth and colleagues, is unpublished but cited in a review article in a peer-reviewed journal ${ }^{[4]}$. This study also showed a MTHFR C677T/T677T polymorphism prevalence of $28 \%$ in Gujrati mothers of babies with Down syndrome. The prevalence of MTHFR C677T/T677T polymorphism in this control population was 54\%. Stuppia and colleagues $^{[10]}$ in their study on 64 mothers of children with Down syndrome and 112 controls from central Italy also found a higher prevalence of mutant $\mathrm{T}$ allele in controls (48\%) than in mothers of children with Down syndrome (44\%). A recent Turkish study also did not find MTHFR C677T polymorphism as a risk factor for Down syndrome among Turkish women ${ }^{[1]]}$.

O'Leary and colleagues ${ }^{[5]}$ investigated 48 Irish mothers who had given birth to babies with Down syndrome and 192 control mothers for MTHFR and MTRR polymorphisms. They found that the frequency of MTRR variant genotypes (A66G) was significantly higher in mothers of children with Down syndrome compared to controls ( $98 \%$ compared to $82 \%, p=0.003$ ) but MTHFR C677T genotype frequencies were not significantly altered in mothers of children with Down syndrome ( $57 \%$ compared to $53 \%, p=0.74$ ).

The role of folate gene polymorphisms as a risk factor for Down syndrome was first evaluated by Hobbs and colleagues ${ }^{[2]}$. The frequencies of MTHFR C677T and MTRR A66G mutations 
were evaluated in DNA samples of 157 mothers of children with Down syndrome and 144 control mothers. The MTHFR C677T polymorphism was found to be more prevalent in mothers of children with Down syndrome with an odds ratio of 1.91 (95\% CI 1.19-3.05) (68\% in cases compared to $52 \%$ in controls). In addition, homozygous, MTRR A66G polymorphism was independently associated with a 2.57 fold increase in estimated risk (95\% CI: 1.33-4.99). The combined presence of both polymorphisms was associated with a greater risk of Down syndrome than was the presence of either alone, with an odds ratio of 4.08 (95\% CI: 1.94-8.56). James et al. ${ }^{[3]}$ evaluated the frequency of the MTHFR C677T polymorphism in 57 mothers of children with Down syndrome and in 50 age-matched control mothers. Mothers with the C677T polymorphism had a 2.6 fold higher risk of having a child with Down syndrome than did mothers without this polymorphism. (95\%CI: 1.2-5.8, $p<0.03$ ).

Our data demonstrates that, while the incidence of Down syndrome in the Indian population is not very different from other ethnic groups, the MTHFR C677T polymorphism is not associated with an increased risk of Down syndrome ${ }^{[12-14]}$. The role of other polymorphisms like MTRR A66G needs to be evaluated as a risk factor for Down syndrome in north Indian mothers. Our study also suggests that the prevalence of the MTHFR C677T polymorphism in north Indian mothers is less than that reported in the Caucasian population. The results of available studies are summarised in TABLE 3.

In our study, we measured homocysteine levels for 92 mothers of babies with Down syndrome and 91 control mothers. Our data showed significantly higher random plasma homocysteine levels in controls compared to mothers of babies with Down syndrome (17.33 compared to 12.26 $\mu \mathrm{mol} / \mathrm{L}, p=0.001)$. O'Leary and colleagues ${ }^{[5]}$ in their study in the Irish population did not find a significant difference in homocysteine levels between cases and controls $(8.40 \pm 2.58$ compared to $8.44 \pm 2.57 \mu \mathrm{mol} / \mathrm{L}, p=0.91)$. The MTRR genotype in their study did not cause any increase in homocysteine after adjusting for Vitamin B12, folate and MTHFR status. The MTHFR genotype in their study, although not significant in the case group, was shown to be an indicator of homocysteine status in the control group.

James and colleagues ${ }^{[3]}$ in their study in the North American population, found that mean fasting plasma homocysteine concentrations in the mothers of children with Down syndrome with one or both C677T alleles was $12.0 \mu \mathrm{mol} / \mathrm{L}$ compared to $8.3 \mu \mathrm{mol} / \mathrm{L}$ in corresponding control mothers. Interestingly, mothers of children with Down syndrome with the more common C677C genotype also had mean homocysteine concentrations that were significantly higher than those of control mothers with the C677C genotype $(10.9$ compared to $7.9 \mu \mathrm{mol} / \mathrm{L})$. The ratio of homocysteine to methionine was significantly higher in mothers of children with Down syndrome than in control mothers, independent of the genotype. These observations suggest that factors other than the C677T polymorphism alter homocysteine and methionine concentrations in mothers of children with Down syndrome. The unpublished study on Gujrati females by Sheth and colleagues ${ }^{[4]}$ found significantly increased homocysteine levels in mothers of babies with Down syndrome compared to control mothers $(8.81 \pm 2.4$ compared to $6.41 \pm 1.8 \mu \mathrm{mol} / \mathrm{L}, p=$ $0.025)$.

We can offer no plausible explanation for the observation that homocysteine levels were higher in controls compared to cases. Another interesting observation was that homocysteine levels in our study were higher when compared to other studies. The possible reasons for this could be widespread methylcobolamin deficiency and possibly other genetic factors in our population $^{[15]}$, use of random rather than fasting plasma samples in our study and also low folate intake in the Indian diet, a fact that is clearly brought out by our data. High homocysteine levels are known to be associated with number of adverse outcomes (e.g. Coronary Artery Disease), a fact which is of concern. We would recommend measurement of fasting homocysteine levels in our population before any further intervention.

We calculated dietary folate intake from dietary history taken by 24 hour recall method. ICMR charts were used to calculate folate intake ${ }^{[9]}$. Mean folate intake was lower than the recommended $400 \mu \mathrm{g}$ daily in both cases and controls but the difference between two groups was not significant (157.63 compared to 143.39). James and colleagues ${ }^{[3]}$ in their study in North American mothers of babies with Down syndrome found a low folate intake $(263 \mu \mathrm{g} /$ day in those with the C/C genotype and $274 \mu \mathrm{g} /$ day for the CT and TT genotypes). Low folate intake could possibly be one of the factors which could explain higher homocysteine levels in the Indian population. Low folate intake could also possibly increase the risk of Neural tube defects in our population. Our data presents a strong case for folate supplementation in the study population.

The MTHFR C677T polymorphism is one of the classical cases of gene nutrient interaction as this polymorphism raises the dietary need of folate to maintain normal homocysteine levels. Only in MTHFR C677T positive cases we could 
demonstrate a non significant negative correlation between folate intake and homocysteine levels.

In summary, the prevalence of the MTHFR C677T polymorphism in north Indian mothers of babies with trisomy 21 Down syndrome was $28 \%$ compared to $35 \%$ in controls (C677T/ T677T). This figure is lower than the reported prevalence in the Caucasian population.

Our data demonstrates that the MTHFR C677T polymorphism is not associated with an increased risk of Down syndrome in the north Indian pop- ulation. Homocysteine levels in our study were higher when compared to other studies. Methylcobolamin, folate deficiency or use of random samples for homocysteine determination could possibly account for this observation. We have no plausible explanation for the observation that homocysteine levels were higher in controls compared to cases. Mean folate intake in both our groups was lower than recommended $400 \mu \mathrm{g} /$ day; however, no correlation between homocysteine levels and folate intake could be demonstrated.
1. Epstein CJ. Down syndrome. In: Scriver CR, Beaudet AL, Sly WS and Valle D, editors. The Metabolic and Molecular Bases of Inherited Disease, Vol. 1, 8th edn. McGraw-Hill; 2001, p. 1223-1256.

2. Hobbs CA, Sherman SL, Yi P, Hopkins SE, Torfs $C P$, Hine RJ, Pogribna M, Rozen R, James SJ. Polymorphisms in genes involved in folate metabolism as maternal risk factor for Down syndrome. American Journal of Human Genetics, 2000;67: 623-630.

3. James SJ, Pogribna M, Pogribny IP, Melnyk S, Hine RJ, Gibson JB, Yi P, Tafoya DL, Swenson DH, Wilson VL, Gaylor DW. Abnormal folate metabolism and mutation in methylenetetrahydrofolate reductase gene may be maternal risk factor for Down syndrome. American Journal of Clinical Nutrition. 1999;70:495-501.

4. Sheth JG, Sheth FJ. Gene polymorphism and folate metabolism: A maternal risk factor for Down syndrome. Indian Pediatrics. 2003;40:115123.

5. O'Leary VB, Parle-McDermott A, Molloy AM Kirke PN, Johnson Z, Conley M, Scott JM, Mills JL. MTRR and MTHFR polymorphism. Link to Down syndrome? American Journal of Medical Genetics. 2002;107:151-155.

6. Miller SA, Dykes DD, Polesky HF. A simple salting out procedure for extracting DNA from human nucleated cells. Nucleic Acids Research. 1988;16: 1215.
7. Yu J, Chen B, Zhana G, Fu S, Li P. The C677T mutation in the Methylenete-trahydrofolate Reductase (MTHFR) gene in five Chinese ethnic groups. Human Heredity. 2000;50:268-270.

8. Axis, Homocysteine EIA, Package insert. Axis-Shield AS, P.O. Box 206 Okern, Ul-venv 87, $\mathrm{N}-0510$ Oslo, Norway.

9. Gopalan C, Rama sastri BV, Balasubramaniam SC. In: Nutritive value of Indian foods. Hyderabad: National Institute of Nutrition (ICMR).1978.

10. Stuppia L, Gatta V, Gaspari AR, Antonucci I, Morizio E, Calabrese G, Palka G. C677T mutation in the 5, 10-MTHFR gene and risk of Down syndrome in Italy. European Journal of Human Genetics. 2002;10:388-390.

11. Boduroglu K, Alanay Y, Koldan B, Tuncbilek E. Methylenetetrahydrofolate reductase enzyme polymorphisms as maternal risk for Down syndrome among Turkish women. American Journal of Medical Genetics. 2004;127A:5-10.

12. Isaac GS, Krishnamurty PS, Reddy YR, Ahuja YR Down's syndrome in Hyderabad, India. Acta anthropogenetica. 1985;9:256-260.

13. Lau TK, Fung HY, Rogers MS, Cheung KL. Racial variation in incidence of trisomy 21: survey of 57,742 Chinese deliveries. American Journal of Medical Genetics. 1998; 75:386-388.

14. Mikkelsen M, Fischer G, Stene J, Stene E, Petersen E. Incidence study of Down's syndrome in Copenhagen, 1960-1971; with chromosome investigation. Annals of Human Genetics. 1976; 40:177-182.

15. Refsum H, Yajnik CS, Gadkari M, Schneede J, Vollset SE, Orning L, Guttormsen AB, Joglekar A, Sayyad MG, Ulvik A, Ueland PM. Hyperhomocysteinemia and elevated methylmalonic acid indicate a high prevalence of cobolamin deficiency in asian Indians. American Journal of Clinical Nutrition. 2001;74:233-241.

Author contributions: UK, MK and SG developed the study protocol and were involved in patient screening and enrolment. Sampling of patients was done by UK. MK and UK, reviewed the literature, analysed the data and wrote the manuscript. MK provided lab support for determination of MTHFR polymorphism. SA did MTHFR polymorphism analysis. $R L$ provided lab support for measurement of homocysteine levels. RMP was involved in the statistical analysis. MK would act as the guarantor of the paper.

Competing interests statement: The authors declare no competing financial interests.

Received: 4 September 2006; Accepted 14 February 2007; Published online: 10 August 2007. 